\title{
Impact of Acne Vulgaris on Patients' Quality of Life
}

\author{
NOHA E. MOHAMAD, M.D. ${ }^{1}$; SAWSAN Kh. ELSAYED, M.D. ${ }^{2}$; LAILA A. REFAAT, M.D. ${ }^{3}$ and \\ WESAM MORAD, M.D. ${ }^{4}$ \\ The Department of Dermatology \& Venereology, Faculty of Medicine, Fayoum University ${ }^{1}$ and \\ Faculty of Medicine for Girls, Al-Azhar University ${ }^{2}$, The Department of Community Medicine, Faculty of Medicine for Girls, \\ Al-Azhar University ${ }^{3}$ and The Department of Epidemiology \& Preventive Medicine, National Liver Institute, Menoufia University
}

\begin{abstract}
Background: Acne is a common inflammatory skin disorder manifested by comedones, papules and pustules mainly at face. Acne may be complicated by nodules, cysts and residual scarring that affect life quality.

Aim of Study: Was to determine the impact of acne on health related quality of life comparing with normal healthy control.

Patients and Methods: The current study included 400 subjects aged from 13 to 18 years old. They were divided into patients' group and control group, each included 200 subjects with age and sex matched. The patients group with mean age of (15.6 \pm 1.54$)$; the female patients constituted $113(56.5 \%)$. According to acne severity, the patient group included moderate acne (117) patients and severe acne in 83 patients. The control group included 114 (57\%) females. Full history taking, general examination including measuring of BMI, dermatologic examination to determine site, extent and grading.
\end{abstract}

Results: Acne negatively affects self-perception in comparison with control while no difference in social role between cases and control. There is a positive correlation between self-perception and the other domains, while there is a negative correlation between acne symptoms and other domains of quality of life.

Conclusions: Acne can affects social and psychologic impact on life quality.

Recommendations: Assessment of life quality in acne patients is a must and should be taken into consideration before deciding line of treatment.

Key Words: Acne - Quality of life-Self-perception.

\section{Introduction}

ACNE is the most common recurrent inflammatory disease of the pilosebaceous units. The earliest subclinical 'lesion' in acne is microcomedone that

Correspondence to: Dr. Wesam Saber Morad, E-Mail: wesammorad@gmail.com may change into closed and open comedones and into some inflammatory lesions, such as papules, cysts. nodules, and pustules. It occurs mainly at sites rich in sebaceous glands like face $(99 \%)$, back $(60 \%)$ and chest (15\%). Acne usually continues beyond the age of 25 years, while some acne patients carry it into their forties. During the healing process, scarring may be the end result of skin damage with a significant impact on quality of life [1].

Acne is often misunderstood as a simple puberty related condition while it is revealed that acne impress patients more than a simple skin disease [2].

Although acne doesn't threaten life, studies have shown that serious problems in patients' body image, socialization, and self-esteem have been observed as social and psychological impacts of acne. Acne is comparable with disabling diseases such as asthma, diabetes, back pain, epilepsy, or arthritis so, attention to the life quality of acne patients is of a high importance [3] .

Health-Related Quality of Life (HRQOL) is the physical, emotional, psychological, and social well-being and functioning recorded by patients. Current acne therapy often contains HRQOL assessment from the negative acne impact on a patient's life quality [4].

Several acne-specific HRQOL questionnaires have been validated and vary in both content and number of items addressing life quality [5] .

\section{Aim of the study:}

Was to determine the impact of acne on health related quality of life comparing with normal healthy control. 


\section{Patients and Methods}

\section{Subjects:}

This was a case-control study that conducted over a period of one year (between January 2018 and January 2019) in El-Fayoum University Hospital, total sample was 400 subjects, aged from 13 to 18 years old. We divided them into two groups:

A- The patients' group: Included 200 cases of moderate and severe acne with mean age (15.6 \pm 1.54); the female patients constituted 113 (56.5\%) patients. According to acne severity, the patient group included moderate acne in 117 patients and severe acne in 83 patients.

$B$ - The control group: Included 200 healthy persons, $114(57 \%)$ of them are female, with age and sex matched.

\section{Exclusion criteria:}

We excluded any patient who refuse to answer the questionnaire and patient with any other associated skin disease, we also excluded patients with any systemic diseases affecting the quality of life.

\section{Method and tools of the study:}

Researcher administered questionnaire was used as a tool for data collection in the study it contains: Socio demographic data, history taking focusing on the special habits, menstrual history, family history for acne, food habits. Clinical examination data to exclude systemic diseases and dermatological examination to grade the severity of acne and to exclude any associated skin disease.

Quality of life was assessed using Acne-QOL questionnaire.

The Acne-QOL questionnaire contains 19 questions, which are organized into four domains (selfperception, role-social, role-emotional, acne symptoms). Acne-QOL domain scores were calculated by summing all items within a domain. Responses for all items are on a scale from:

0 for very extensive, 2 for extensive, 4 for average and, 6 for none with each item within a domain weighted equally. For all domains, higher scores reflect better HRQoL.

\section{Ethical approval:}

The study protocol was approved by the ethical review board and the parents of every participant signed an Arabic consent form in front of the authors. The consent form stated that the result would be anonymous and would be used only for scientific purposes.

\section{Results}

Table (1): Showed the sociodemographic profile of the studied groups, the mean age was $(15.6 \pm$ $1.54)$ years of cases and $(15.5 \pm 1.4)$ years for controls, this difference was statistically non-significant $(p$-value $>0.05)$.

Table (1): Some sociodemographic profile of the studied group.

\begin{tabular}{|c|c|c|c|c|c|c|}
\hline $\begin{array}{l}\text { Groups } \\
\text { Variables }\end{array}$ & \multicolumn{2}{|c|}{$\begin{array}{l}\text { Patient } \\
\text { group } \\
\text { No.=200 }\end{array}$} & \multicolumn{2}{|c|}{$\begin{array}{l}\text { Control } \\
\text { group } \\
\text { No. }=200\end{array}$} & Sig. test & $\underset{\text { value }}{p^{-}}$ \\
\hline $\begin{array}{l}\text { Agelyear: } \\
\text { - Mean } \pm \mathrm{SD}\end{array}$ & $15.6=$ & $=1.54$ & $15.5^{ \pm}$ & $=1.4$ & $t$-test $=1.0$ & $p=0.27$ \\
\hline $\begin{array}{l}\text { Sex: } \\
\text { - Male } \\
\text { - Female }\end{array}$ & $\begin{array}{l}\text { No.= } \\
200 \\
87 \\
113\end{array}$ & $\begin{array}{c}\% \\
43.5 \\
56.5\end{array}$ & $\begin{array}{l}\text { No.= } \\
200 \\
86 \\
114\end{array}$ & $\begin{array}{c}\% \\
43.0 \\
57.0\end{array}$ & 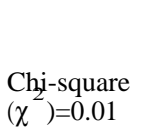 & $p=0.9$ \\
\hline $\begin{array}{l}\text { Occupation: } \\
\text { - Student } \\
\text { - None worker } \\
\text { - Skilled worker } \\
\text { - Unskilled worker }\end{array}$ & $\begin{array}{l}160 \\
17 \\
11 \\
12\end{array}$ & $\begin{array}{l}80.0 \\
8.5 \\
5.5 \\
6.0\end{array}$ & $\begin{array}{l}168 \\
12 \\
9 \\
11\end{array}$ & $\begin{array}{l}84.0 \\
6.0 \\
4.5 \\
5.5\end{array}$ & $\begin{array}{l}\text { Chi-square } \\
(\chi)=1.3\end{array}$ & $p=0.7$ \\
\hline $\begin{array}{l}\text { Educational level: } \\
\text { - Preparatory } \\
\text { - Secondary } \\
\text { - University }\end{array}$ & $\begin{array}{l}119 \\
76 \\
5\end{array}$ & $\begin{array}{l}59.5 \\
38.0 \\
2.5\end{array}$ & $\begin{array}{l}135 \\
57 \\
7\end{array}$ & $\begin{array}{l}67.8 \\
28.6 \\
3.5\end{array}$ & $\begin{array}{l}\text { Chi-square } \\
(\chi)=4.0\end{array}$ & $p=0.13$ \\
\hline $\begin{array}{l}\text { Special habit: } \\
\text { - No } \\
\text { - Smoking }\end{array}$ & $\begin{array}{l}192 \\
8\end{array}$ & $\begin{array}{l}96.0 \\
4.0\end{array}$ & $\begin{array}{l}189 \\
11\end{array}$ & $\begin{array}{l}94.5 \\
5.5\end{array}$ & $\begin{array}{l}\text { Chi-square } \\
(\chi)=0.49\end{array}$ & $p=0.4$ \\
\hline
\end{tabular}

In patients group, the female patients represented 113 patients $(56.5 \%)$, while in controls the female were 114 patients (57\%), this difference was statistically non-significant ( $p$-value $>0.05)$.

As regards to educational level of cases 119 $(59.5 \%)$ were preparatory, secondary $76(38.0 \%)$ and university 5 (2.5\%), compared to $135(67.8 \%)$, $57(28.6 \%)$, and 7 (3.5\%) in control respectively, this difference was statistically non-significant ( $p$ value $>0.05$ )

Occupations of cases as student (80\%), skilled worker $(5.5 \%)$, unskilled worker $(6 \%)$ and nonworker $(8.5 \%)$ compared to $(84 \%, 4.5 \%, 5.5 \%$ and $6 \%$ ) of control group respectively, this difference was statistically non-significant ( $p$-value $>0.05$ ).

There were $(96 \%)$ of cases don't have any special habit, while (4\%) of them were smokers compared to $(94.5 \%)$ and $(5.5 \%)$ of control group respectively, this difference was statistically nonsignificant ( $p$-value $>0.05)$.

Table (2): Showed the comparison between patients and control regarding self-perception and social role. The mean of self-perception were $(19.52$ 
$\pm 8.49)$ and $(21.9 \pm 8.395)$ among cases and control respectively, this difference was statistically significant $(p$-value $<0.05)$.

Table (2): Comparison between acne cases and control regarding mean scores of self-perception and social role.

\begin{tabular}{lllll}
\hline Group & $\begin{array}{c}\text { Acne cases } \\
\text { No.=200 } \\
\text { Mean } \pm \text { SD }\end{array}$ & $\begin{array}{c}\text { Control } \\
\text { No.=200 } \\
\text { Mean } \pm \text { SD }\end{array}$ & Sig.test & $p$-value \\
\hline Self perception & $19.52 \pm 8.49$ & $21.9 \pm 8.395$ & $t$-test $=2.85$ & $p=0.005^{*}$ \\
Social role & $18.82 \pm 7.0$ & $19.5 \pm 6.9$ & $t$-test $=0.96$ & $p=0.33$ \\
\hline
\end{tabular}

$*: p$-value is significant at $\leq 0.05$.

While the mean of social role were $(18.82 \pm 7.0)$ and (19.5 \pm 6.9$)$ among cases and control respectively, this difference was statistically nonsignificant ( $p$-value $>0.05)$.

Table (3): Show comparison between moderate and severe acne patients, the mean of self-perception and acne symptom of moderate acne patient were $(20.6 \pm 8.6)$ and $(12.1 \pm 7.0)$ respectively, while for severe acne patient were $(17.9 \pm 8.2)$ and $(9.3 \pm$ $4.3)$ respectively.

Table (3): Comparison between moderate and severe acne patients regarding quality of life domains.

\begin{tabular}{|c|c|c|c|c|}
\hline $\begin{array}{l}\text { Severity } \\
\text { Acne } \\
\text { score }\end{array}$ & $\begin{array}{c}\text { Moderate } \\
\text { No. }=117 \\
\text { Mean } \pm \text { SD }\end{array}$ & $\begin{array}{c}\text { Severe } \\
\text { No. }=83 \\
\text { Mean } \pm \text { SD }\end{array}$ & Sig.test & $p$-value \\
\hline Social role & $19.16 \pm 7.0$ & $18.3 \pm 7.14$ & $t$-test $=0.8$ & $p=0.4$ \\
\hline Role emotional & $21.2 \pm 11.5$ & $20.5 \pm 10.7$ & $t$-test $=0.4$ & $p=0.6$ \\
\hline Self perception & $20.6 \pm 8.6$ & $17.9 \pm 8.2$ & $t$-test $=2.2$ & $p=0.02 *$ \\
\hline Acne symptoms & $12.1 \pm 7.0$ & $9.3 \pm 4.3$ & $t$-test $=3.1$ & $p=0.002 *$ \\
\hline
\end{tabular}

$*: p$-value is significant at $\leq 0.05$.

There was statistically significant difference between moderate acne patients and severe acne patients regarding self-perception and acne symptoms domains ( $p$-value $<0.05)$.

While no significant difference regarding other domains. ( $p$-value >0.05).

Fig. (1): Showed the comparison between patients by site of acne regarding quality of life domains. The mean score of social role at patients with face only was $(17.8 \pm 7.1)$, while the mean score for patients with acne at both face and trunk was $(20.7 \pm 6.6)$, this was statistically significant ( $p$-value $<0.05)$. While the mean of self-perception, emotional role, and acne symptoms domains at patients with acne at face only were (19.2 \pm 8.3 , $20.5 \pm 11.1$, and $10.9 \pm 6.4$ ) respectively compared to $(20.2 \pm 8.8,21.7 \pm 11.5$, and $11.0 \pm 5.8)$ at patients with acne at both face and trunk, this difference was statistically non-significant ( $p$-value $>0.05$ ).

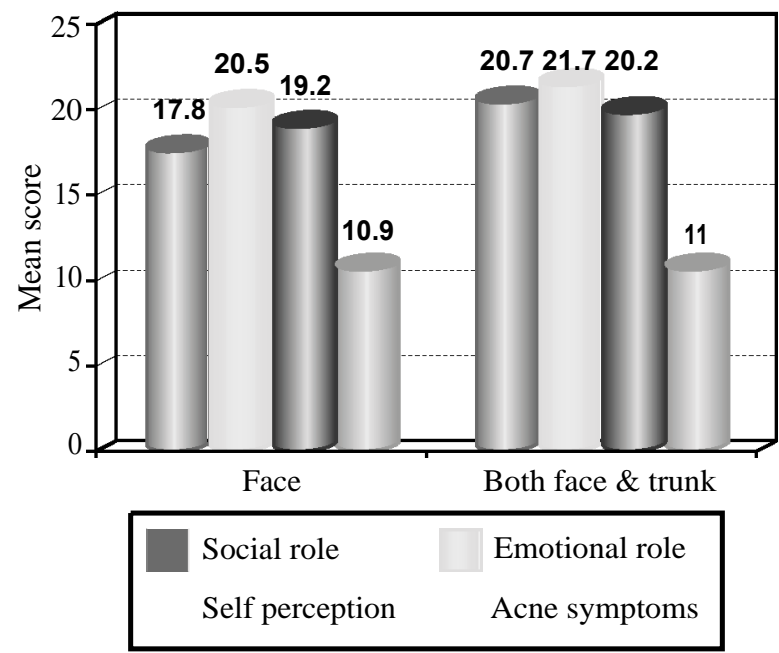

Fig. (1): Comparison between patients by site of acne regarding quality of life domains.

Table (4): Showed the comparison between male and female cases regarding quality of life domains, the mean of emotional role at male was $(22.8 \pm 10.9)$ compared to $(19.4 \pm 11.2)$ at female patients, this was statistically significant ( $p$-value $<0.05)$.

Table (4): Showed the quality of life in patients with acne in regards to gender, family history and menstrual irregularity.

\begin{tabular}{|c|c|c|c|c|}
\hline $\begin{array}{lr} & \text { Severity } \\
\text { Acne } & \text { of } \\
\text { score } & \\
\end{array}$ & $\begin{array}{c}\text { Male } \\
\text { No. }=87 \\
\text { Mean } \pm \text { SD }\end{array}$ & $\begin{array}{c}\text { Female } \\
\text { No. }=113 \\
\text { Mean } \pm \text { SD }\end{array}$ & Sig.test & $p$-value \\
\hline Self perception & $19.3 \pm 8.1$ & $19.7 \pm 8.7$ & $t$-test $=0.46$ & $p=0.6$ \\
\hline Role social & $18.2 \pm 6.8$ & $19.2 \pm 7.2$ & $t$-test $=0.24$ & $p=0.8$ \\
\hline Role emotional & $22.8 \pm 10.9$ & $19.4 \pm 11.2$ & $t$-test $=2.1$ & $p=0.03 *$ \\
\hline Acne symptoms & $11.2 \pm 6.3$ & $10.8 \pm 6.1$ & $t$-test $=0.5$ & $p=0.06$ \\
\hline $\begin{array}{l}\text { Family } \\
\text { history }\end{array}$ & $\begin{array}{c}\text { Negative } \\
\text { family history } \\
\text { No. }=86 \\
\text { Mean } \pm \text { SD }\end{array}$ & $\begin{array}{c}\text { Positive } \\
\text { family history } \\
\text { No. }=114 \\
\text { Mean } \pm \text { SD }\end{array}$ & Sig.test & $p$-value \\
\hline Self-perception & $19.5 \pm 8.3$ & $19.4 \pm 8.6$ & $t$-test $=0.04$ & $p=0.9$ \\
\hline Role social & $17.3 \pm 7.47$ & $20.7 \pm 6.0$ & $t$-test $=3.38$ & $p=0.001 *$ \\
\hline Role emotional & $19.9 \pm 11.5$ & $22.3 \pm 10.6$ & $t$-test $=1.4$ & $p=0.1$ \\
\hline Acne symptoms & $11.2 \pm 6.3$ & $10.7 \pm 6.1$ & $t$-test $=0.6$ & $p=0.5$ \\
\hline Score & $\begin{array}{c}\text { Regular } \\
\text { menstrual } \\
\text { history } \\
\text { No.=62 } \\
\text { Mean } \pm \text { SD }\end{array}$ & $\begin{array}{c}\text { Irregular } \\
\text { menstrual } \\
\text { history } \\
\text { No.=51 } \\
\text { Mean } \pm \text { SD }\end{array}$ & Sig.test & $p$-value \\
\hline Self-perception & $18.5 \pm 8.2$ & $21.0 \pm 9.3$ & $t$-test $=1.5$ & $p=0.13$ \\
\hline Role social & $17.7 \pm 7.5$ & $21.2 \pm 6.4$ & $t$-test $=2.5$ & $p=0.012 *$ \\
\hline Role emotional & $18.8 \pm 10.8$ & $20.2 \pm 11.8$ & $t$-test $=0.63$ & $p=1.3$ \\
\hline Acne symptoms & $11.4 \pm 6.7$ & $10.0 \pm 5.1$ & $t$-test $=1.2$ & $p=0.2$ \\
\hline
\end{tabular}

$*$ : $p$-value is significant at $\leq 0.05$.

While the mean of self-perception, social role, and acne symptoms domains at male patients were $(19.3 \pm 8.1,18.2 \pm 6.8$, and $11.2 \pm 6.3)$ respectively, 
compared to $(19.7 \pm 8.7,19.2 \pm 7.2$, and $10.8 \pm 6.1)$ at female patients respectively, this was statistically non-significant ( $p$-value $>0.05$ ).

In regards to the family history the mean of social role of in patients positive family history patients was $(20.7 \pm 6.0)$ compared to $(17.3 \pm 7.47)$ in patients with negative family history, this difference was statistically significant ( $p$-value $<0.05$ ). While the mean of self-perception, emotional role, and acne symptoms domains at positive family history acne patients were (19.4 $\pm 8.6,22.3 \pm 10.6$ and $10.7 \pm 6.1)$ respectively compared to $(19.5 \pm 8.3$, $19.9 \pm 11.5$, and $11.2 \pm 6.3$ ) at negative family history patients, this difference was statistically nonsignificant ( $p$-value $>0.05$ ) (Table 3$)$.

It was noticed that the mean of social role at female patients with regular menstrual history was (17.7 \pm 7.5$)$ and at female patients with irregular menstrual history was $(21.2 \pm 6.4)$ this difference was statistically significant ( $p$-value $<0.05$ ). While the mean of self-perception, emotional role, and acne symptoms domains at regular menstrual history acne patients were $(18.5 \pm 8.2,18.8 \pm 10.8$, and $11.4 \pm 6.7)$ respectively compared to $(21.0 \pm 9.3,20.2$ \pm 11.8 , and $10.0 \pm 5.1$ ) at irregular menstrual history patients, this difference was statistically nonsignificant ( $p$-value $>0.05$ ) (Table 3 ).

Fig. (2): Illustrated comparison between the grades of BMI of acne patients regarding quality of life domains. It was noticed that the mean of self-perception, social role, emotional role, and acne symptoms domains at under wt patients were $(18.3 \pm 8.8,17.8 \pm 7.2,21.7 \pm 9.0$ and $10.1 \pm 4.9)$ respectively compared to $(19.5 \pm 8.7,18.1 \pm 7.0,20.0 \pm$ 10.4 , and $11.7 \pm 6.9)$ for normal wt patients, while for over wt acne patients were $(19.8 \pm 8.2,19.7 \pm 7.0$, $21.6 \pm 12.5$, and $10.4 \pm 5.7)$ respectively, this difference was statistically non-significant ( $p$-value $>0.05$ ).

Table (5): Showed the correlation between quality of life domains and age of acne patients. There was a positive significant correlation between age of acne patients and acne symptoms ( $p$-value $<0.05)$. While theis correlation was non-significant among other domains of quality of life ( $p$-value $>0.05$ ).

Table (5): Correlation between quality of life domains and duration of the disease among acne patients. There was no significant correlation between quality of life domains and duration of the disease $(p$-value $>0.05)$.

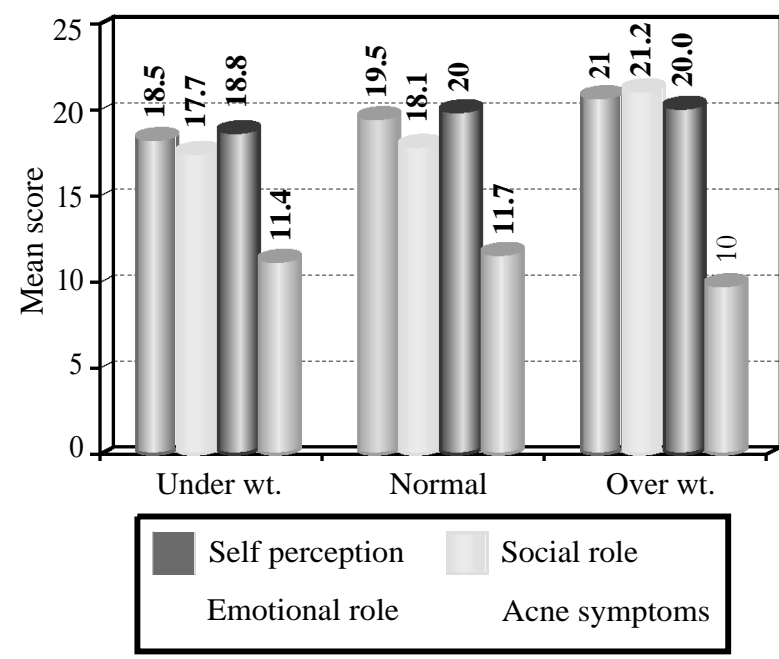

Fig. (2): Quality of life domains and grades of BMI among patient group.

Table (5): Correlation between quality of life domains and age of patients and duration of disease.

\begin{tabular}{lll}
\hline Variables & Correlation coefficient $(r)$ & $p$-value \\
\hline Age/year: & & \\
* Self perception & 0.06 & 0.34 \\
* Acne symptoms & 0.16 & $0.01 *$ \\
* Social role & 0.11 & 0.09 \\
* Emotional role & 0.04 & 0.5 \\
Duration/months: & & \\
* Self perception & 0.006 & 0.9 \\
* Social role & 0.122 & 0.08 \\
* Emotional role & 0.025 & 0.7 \\
$*$ Acne symptoms & 0.134 & 0.06 \\
\hline
\end{tabular}

**: Correlation is significant at the 0.01 level.

* : Correlation is significant at the 0.05 level.

\section{Discussion}

Acne was more likely to be developed than any other dermatologic disease in patients lifetime. Recently, the psychodermatologic literature will begin to detect the possibility of having psychological and emotional impact of acne. Although there was an association between acne and psychological impact which had been debated for many years, only recent studies will focus on shift from psychological correlates and emotional triggers to the impact of acne on self-esteem and patients' quality of life [7].

In this case-control study, we included 400 subjects and we divided them into 2 groups, the patients group was divided into 200 patients with acne with different severities. We compared both groups in regards to the quality of life which was assessed using the specific Acne-QOL questionnaire [6].

In this study, we found that there was a statistical significant difference both groups regarding the 
self-perception domain, while no significant difference was found regarding social role, this could be explained as both groups were of teenager if they had acne or not they felt fear from going out to public and met new people especially interacting with other gener $[8]$. Our findings in the current study, go online with other studies $[\mathbf{7 , 9 , 1 0 ]}$.

In our study we found that in the patients group there was a correlation between Acne-QOL domain scores in acne group, we found a significant negative correlation between acne symptoms and quality of life score. This could be explained by the fear of scarring resulted in frustration and being bored from treatment [11]. Similar studies had reported similar data $[\mathbf{5 , 7 , 8 , 1 1 - 1 3 ]}$.

In regards to the self-perception, we found a significant positive correlation between selfperception and the other QOL domains which could be explained by that self-perception is a very Influential at other domains once improved, quality of life of the patient would be improved. This was in agree with Kamamoto et al. [10].

In the current study, we found that a statistical significant association between the grade of acne severity and QOL impairment. Increase acne severity was associated with increase the awareness, sensitivity, negative feeling and anxiety. Many authors had reported similar results to ours [13-16] However, on the contrary to our study, Boon-Bin Yap, Kamamoto et al., found that there was no association between acne and the patients' quality of life $[\mathbf{8 , 1 0 ]}$.

In our study, Acne which located at face affected the social life more than patients with acne located at both face and trunk. Given that, in Islamic countries like Egypt, the trunk was not exposed to others, so lesions at face only made patients more aware by their lesions. This agreed with Ludwig et al. [17].

In our study, the females' quality of life were significantly more affected than males. This could be explained by females which were more sensitive about their appearance.

On the same line e.g. Ismail and MohammedAli, [14] had reported similar findings to ours. However, Safizadeh et al., [18] found that no significant association between the patients' quality of life and the gender of the patients.

In our study, we found that positive family history patients had worse quality of life score than negative family history patients; this might be explained by feeling fear from being like their family suffering from sequelae of disease like scarring. However, Tasoula et al., [11] found that patients with acne, the family history had no impact on the patients' quality of life.

In our study, we had evaluated the impact of menstrual history in the patients quality of life in patients with acne, we found that acne patients with irregular menstrual history had worse quality of life than regular menstrual history this could be explained by more severe variant of acne which was associated with menstrual irregularity. Similar findings had been reported by Barnes et al., [5] However, the menstrual irregularity itself impaired quality of life [19].

In our study, we also evaluated the impact of obesity on the patients quality of life in patients with acne, we found that no significant association between BMI grades of patients with acne regarding quality of life scores and this might be due to the acne itself which impaired the quality of life not body size and this agreed with other studies $[11,20]$.

In the current study, we found a significant correlation between age of patient and quality of life impairment, this could be explained by the patients with acne percept that acne disappeared with age, while its persistence, new lesions appearance and development of scar tissues as consequences of acne lesions, all were opposite of the patients' perception. Similar results were reported in other studies $[\mathbf{1 1}, 14]$.

In the present study, we found no significant relationship between the quality of life and the duration of diseases. Safizadeh et al., [18] and Kokandi, [3] reported similar finding to ours. This could be explained by the long standing of the disease, which improved patient ability to accept the disease and increase their coping with acne disease burden.

However, Kamamoto et al., [10] Tan et al., [21] reported that with the longstanding of the disease, the patients' quality of life was decreased. The discrepancy in results could be postulated to that heterogeneity of included patients in regards to the duration of illness and geographical distributions with different lifestyles.

This study was limited as patients with post acne scars were not included in this study and the impact of treatment on the patients' quality of life was not studied. 
The strengths of this study were many and included the use of large number of patients and controls, the use of validated questionnaire in its Arabic version and the use of all items of questionnaire which improved the validity of our study.

\section{Conclusions and Recommendations:}

In conclusion, acne negatively affected selfperception but without significant impact on the social role. There was a positive correlation between self-perception and the other domains, while there was a negative correlation between acne symptoms and other domains of quality of life. Also there was a significant association between severity of acne and quality of life impairment. Acne affected the quality of life of females more than males. Positive patients' family history had worse the quality of life than negative family history patients. Quality of life was more affected in patients with irregular menstrual history. The older the age of patients the more impairment to quality of life.

\section{References}

1- SAMAR R. EL-TAHLAWI, NOHA EZZAT MOHAMMAD and HEBA SAYED MOHAMED: Survivin and insulin-like growth factor-I: Potential role in the pathogenesis of acne and post-acne scar Scars, burns \& healing j, 2019.

2- S. HANNA, J. SHARMA, and J. KLOTZ: "Acne vulgaris: More than skin deep,"Dermatology Online Journal, 9 (3): 8, 2003.

3- A. KOKANDI: "Evaluation of acne quality of life and clinical severity in acne female adults," Dermatology Research and Practice, Vol. 2010, Article ID 410809, 3 pages, 2010.

4- BALKRISHNAN R., McMICHAEL A.J., HU J.Y., et al.: Correlates of health-related quality of life in women with severe facial blemishes. Int. J. Dermatol., 45 (2): 111-5, 2006.

5- LAUREN E. BARNES, MICHELLE M. LEVENDER, ALAN B. FLEISCHER Jr. and STEVEN R. FELDMAN: Quality of LifeMeasures for Acne Patients Dermatol. Clin., 30: 293-300, 2012.

6- TAN J., O'TOOLE A., ZHANG X., DRENO B. and POULIN Y.: Cultural and linguistic validation of acne-QoL in French. J. Eur. Acad. Dermatol. Venereol., 26: 1310-4, 2012.

7- HOSTHOTA A., BONDADE S. and BASAVARAJA V.: Impact of acne vulgaris on quality of life and self-esteem. Cutis, Aug., 98 (2): 121-4, 2016.

8- FELIX BOON-BIN YAP: The impact of acne vulgaris on the quality of life in Sarawak, Malaysia. Journal of the Saudi Society of Dermatology \& Dermatologic Surgery, 16: 57-60, 2012.

9- MARTIN A.R., LOOKINGBILL D.P., BOTEK A., LIGHT J., THIBOUTOT D. and GIRMAN C.J.: Health-related quality of life among patients with facial acne-assessment of a new acne-specific questionnaire. Clin. Exp. Dermatol., 26: 380-5, 2001.
10- CRISTHINE De SOUZA LEAO KAMAMOTO, KARIME MARQUES HASSUN EDILÉIA BAGATIN and JANE TOMIMORI: Acne-specific quality of life questionnaire (Acne-QoL): Translation, cultural adaptation and validation into Brazilian-Portuguese language. An Bras Dermatol., 89 (1): 83-90, 2014.

11- ELENI TASOULA, STAMATIS GREGORIOU, JOHN CHALIKIAS, DIMITRIS LAZAROU, IFIGENIA DANOPOULOU, ANDREAS KATSAMBAS, and DIMITRIS RIGOPOULOS: The impact of acne vulgaris on quality of life and psychic health in young adolescents in Greece. Results of a population surve. An Bras Dermatol., 87 (6): 862-9, 2012.

12- KULTHANAN K., JIAMTON S. and KITTISARAPONG R.: Dermatology Life Quality Index in Thai patients with acne. Siriraj Med. J., 59: 3-7, 2007.

13- CHERNYSHOV P.V., ZOUBOULIS C.C., TOMASARAGONES L., JEMEC G.B., MANOLACHE L., et al.: Quality of life measurement in acne. Position Paper of the European Academy of Dermatology and Venereology Task Forces on Quality of Life and Patient Oriented Outcomes and Acne, Rosacea and Hidradenitis Suppurativa. J. Eur. Acad. Dermatol. Venereol., Feb., 32 (2): 194208. doi: 10.1111/jdv.14585. Epub 2017 Oct. 10, 2018.

14- KAMERAN HASSAN ISMAIL and KHALIS BILAL MOHAMMED-ALI: Quality of life in patients with acne in Erbil city. Health and Quality of Life Outcomes; (6): 10-60, 2012.

15- WALKER N. and LEWIS-JONES M.S.: Quality of life and acne in Scottish adolescent schoolchildren: Use of the Children's Dermatology Life Quality Index (CDLQI) and the Cardiff Acne Disability Index (CADI). JEADV, 20: 45-50, 2006.

16- VILAR G.N., SANTOS L.A. and SOBRAL FILHO J.F.: Quality of life, self-esteem and psychosocial factors in adolescents with acne vulgaris. An Bras Dermatol., Sep.Oct., 90 (5): 622-9, 2015.

17- LUDWIG M.W., OLIVEIRA MDA S., MULLER M.C. and MORAES J.F.: Quality of life and site of the lesion in dermatological patients. An Bras Dermatol., 84 (2): 143-50, 2009.

18- SAFIZADEH H., SHAMSI-MEYMANDY S., and NAEIMI A.: Quality of Life in Iranian Patients with Acne. Dermatology Research and Practice; Article ID 571516: $1-4,2012$.

19- BAZARGANIPOUR F., ZIAEI S., MONTAZERI A., FOROOZANFARD F. and FAGHIHZADEH S.: Iranian version of modified polycystic ovary syndrome healthrelated quality of Life questionnaire: Discriminant and convergent validity. Iran J. Reprod Med., Sep., 11 (9): 753-60, 2013.

20- DALGARD F., GIELER U., HOLM J.O., BJERTNESS E. and HAUSER S.: Self-esteem and body satisfaction among adolescents with acne: Results from a population survey. J. Am. Acad Dermatol., 59: 746-51, 2008.

21- TAN J.K., LI Y., FUNG K., GUPTA A.K., THOMAS D.R., SAPRA S., et al.: Divergence of demographic factors associated with clinical severity compared with quality of life impact in acne. J. Cutan. Med. Surg., 12: 235-42, 2008. 


\section{تآثير حب الشباب الشائع على نوعية حياة الهرضى}

إن حب الثباب هو إضطراب جلدى شائع يتجلى فى كوميلونيس، حطاطات ويثرات بشكل رئيسى فى الوجه، قد يكن حب الشباب معقداً

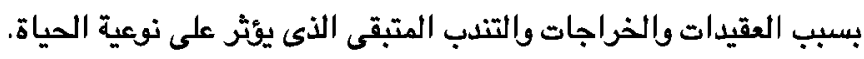

الهدف من الدراسةة: تم تحديد تآثير حب الثباب على جودة الحياة ذات الصلة بالصحة مقارنة مع التحكم الصحى الطبيعى وقد شملت

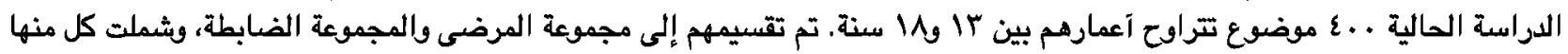

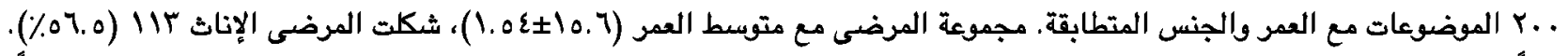

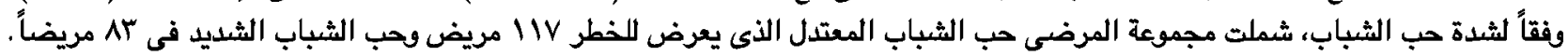

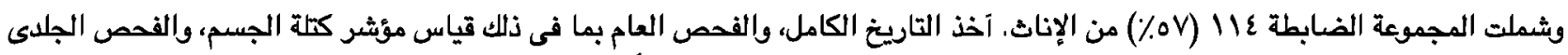

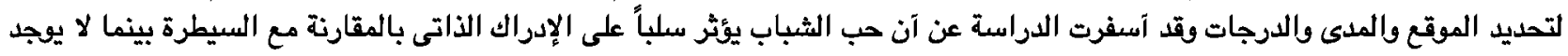

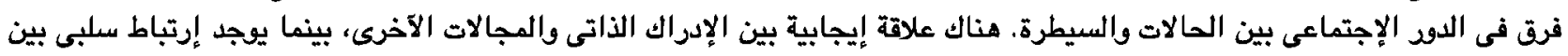

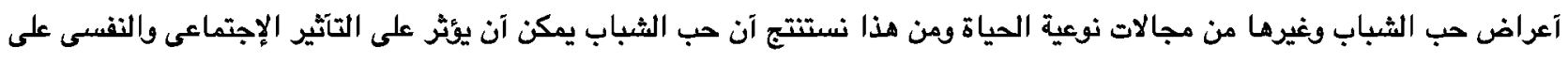

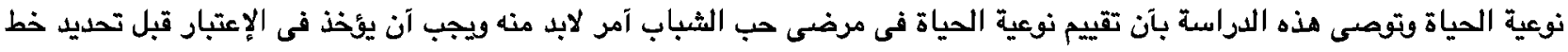
العلاج. 